\title{
A Rational Procedure to Increase Selectivity in the Determination of an Elicitor as Salicylic Acid in Polygala Extracts Using Capillary Electrophoresis
}

\author{
Kheytiany H. S. Lopes, ${ }^{a}$ Tiago Tizziani, ${ }^{\oplus a}$ Ana P. Ruani, ${ }^{a}$ Luciano Vitali ${ }^{a}$ and \\ Gustavo A. Micke ${ }^{\circledR *, a}$ \\ ${ }^{a}$ Departamento de Química, Universidade Federal de Santa Catarina, 88040-900 Florianópolis-SC, Brazil
}

\begin{abstract}
Considering the economic potential of secondary metabolites, researches have been focusing several strategies in order to explore and enhance the accumulation of these metabolites in plant matrices in a broad context. One of those strategies is the development of suitable methodologies for the determination of some elicitors, such as salicylic acid (SA). Since literature presents only a few analytical methods for the quantification of SA in plants, this study developed, validated and evaluated these metabolite contents in Polygala species using capillary zone electrophoresis with ultraviolet-visible detection. The background electrolyte (BGE) consisted of $15 \mathrm{mmol} \mathrm{L}^{-1}$ of hydroxymethyl-aminomethane and $30 \mathrm{mmol} \mathrm{L}^{-1}$ of 2-hydroxy-isobutyric acid, $\mathrm{pH}=3.9$. The BGE was chosen using a rational procedure to increase selectivity and reduce migration time. The method presented rapid performance, migration time less than $0.76 \mathrm{~min}$ for salicylic and phthalic acid (internal standard), precision results for peak area were better than $2.9 \%$ (intra-day) and $2.8 \%$ (inter-day) and the responses for the analytes were linear (range of $1-5 \mathrm{mg} \mathrm{L}^{-1}$ ), with limits of detection and quantification of 0.2 and $0.6 \mathrm{mg} \mathrm{L}^{-1}$, respectively. The developed method was applied for 39 samples of plant extracts.
\end{abstract}

Keywords: salicylic acid, chemical elicitor, Polygala, plant analysis, capillary zone electrophoresis

\section{Introduction}

Salicylic acid (SA) has been used medicinally since the ancient times and is one of the most important simple phenolic compounds from natural products that have received the maximum attention of the scientists worldwide. The intensive research related to SA in plants has unveiled its involvement in diverse physiological and developmental responses: seed germination, stomatal movements, pigment accumulation, photosynthesis, ethylene biosynthesis, heat production, enzyme activities, nutrient uptake, flower induction, membrane functions, legume nodulation and overall plant growth and development. ${ }^{1-3}$ Studies in biotechnology, food and others clearly demonstrate that SA can efficiently recover the biosynthesis of secondary metabolites. Furthermore, recent research ${ }^{1}$ reports that the production of SA in plants does not simply modulate SA antibacterial biosynthetic mechanisms, but also presents relative contributions in the formation of secondary

*e-mail: gustavo.micke@ufsc.br

Editors handled this article: Eduardo Carasek and Rodrigo A. A. Muñoz (Associate) metabolites of the shikimate and phenylpropanoid pathways, demonstrating that the role of SA differs markedly among plant species. Considering the economic potential of secondary metabolites, researches around the world have been developing several strategies in order to explore and enhance the accumulation of these metabolites in plants in a broad context. The literature has brought a large number of studies ${ }^{4,5}$ focusing on the evaluation and the impact of SA on the accumulation of secondary metabolites in different plant species. One of those strategies is the development of suitable methodologies for the determination of SA in plant matrices.

The literature presents a few advantageous analytical methods for the quantification of SA in plants. In addition, the methods for quantification of SA are most focused in drug compositions, samples of pharmaceutical preparations, either by UV, spectrophotometry, spectroscopy by infrared (IR) and chromatographic methods. One of these methodologies uses a reversedphase high performance liquid chromatography (RPHPLC) for the quantification of imiquimod and salicylic acid, two substances commonly found in specific drugs for skin treatment, although it presents some disadvantages, 
as high consumption of organic solvent and time analysis. ${ }^{6}$ A method of simultaneous direct quantification of some phenolic acids, such as salicylic acid and others, in different plant extracts was developed based on the partial least square regression-attenuated total reflectanceFourier transform infrared (PLS-ATR-FTIR) analysis. ${ }^{4}$ However, the method presented a relatively high time for sample preparation and low selectivity when analyzing the phenolic compounds in the extract sample. One recent capillary zone electrophoresis (CZE) method was considered the first CZE method for determining SA, yet it only determines SA in pharmaceutical compositions, specifically in an ointment matrix. Furthermore, this proposed CZE method presents consumption of chlorinated solvents and requires too much time in total analysis time. $^{7}$

Since CZE is a technique widely used to analyze compounds due to low solvent consumption, high analytical frequency, short analysis time and less laborious methodologies for sample preparation, this technique was selected for this work purpose. Recent research shows an absence of any electrophoretic method for the determination of these metabolites in plant matrices.

This paper evaluates a class of plants of the Polygalaceae family, specifically from the genus Polygala L., which is the most abundant one, with 39 species present in Southern Brazil. The most popularly known Polygala in the world, for the great spectra of pharmacological activities, Polygala tenuifolia, ${ }^{8-10}$ from China, and many other species have been presenting many promising studies in the natural products research area. Those plants have been chemically characterized by the presence of potent metabolites in many aspects, such as xanthones, ${ }^{11}$ flavonoids, ${ }^{12}$ triterpene saponins, ${ }^{13}$ polysaccharides, styrylpyrone, coumarins and sterols. ${ }^{14}$ Some in vitro and in vivo studies have shown important biological effects of these plants, such as the anti-inflammatory activity of sterols, ${ }^{15}$ isoflavones and triterpene saponins, ${ }^{16}$ the antitumor activity of polysaccharides and xanthones, ${ }^{17}$ the antidepressant activity of styrylpyrones and the antinociceptive activity of flavonoids. ${ }^{18}$

In this sense, the aim of this study was to evaluate the contents of this elicitor (SA) in Polygala species using CZE as an analytical tool, developing and validating a rapid, green and less laborious method for this proposal. As some of other research papers published by our group, ${ }^{19}$ this work highlights the importance and relevance of using a strategy simulation that provides the creation of analytical methods that do not require greater solvent and analyte quantities, therefore reducing analyte costs for tests, with lower generation of residues.

\section{Experimental}

\section{Chemical and reagents}

All solutions were prepared using analytical grade reagents, solvents of chromatographic purity, and ultrapure water (Milli-Q, Millipore, Bedford, USA). Sodium hydroxide $(\mathrm{NaOH})(\geq 97 \%)$ was supplied by Labsynth (São Paulo, Brazil). Methanol and ethanol were obtained from Tedia (São Paulo, Brazil). $\alpha$-Hydroxyisobutyric acid (HIBA), purchased from Sigma-Aldrich (São Paulo, SP, Brazil) and tris(hydroxymethyl) aminomethane (Tris), purchased from Labsynth (Diadema, SP, Brazil), were used in the background electrolyte (BGE). Standard solutions (1000 $\mathrm{m} \mathrm{L} \mathrm{L}^{-1}$ ) of salicylic acid (SA) and phthalic acid (PA, internal standard) were obtained from Sigma-Aldrich (São Paulo, Brazil) and dilutions were prepared in water daily.

\section{Electrophoretic conditions}

All experiments were performed in a CE system HP $3^{\mathrm{D}}$ (from Agilent Technologies, Palo Alto, USA) equipped with a diode array detector and data treatment software (HP ChemStation).$^{20}$ Separation was carried out in a fusedsilica capillary of $32.0 \mathrm{~cm}$ of total length $(8.5 \mathrm{~cm}$ effective length $\times 50 \mu \mathrm{m}$ I.D. $\times 375 \mu \mathrm{m}$ O.D.) from Polymicro Technologies (Phoenix, USA). The BGE was composed of $15 \mathrm{mmol} \mathrm{L}^{-1}$ Tris and $30 \mathrm{mmol} \mathrm{L}^{-1}$ of HIBA at $\mathrm{pH} 3.9$ (prepared daily). The capillary was conditioned by flushing with $1 \mathrm{~mol} \mathrm{~L}^{-1} \mathrm{NaOH}$, water and BGE for 5 min each. Among runs, the capillary was rinsed for one minute with the BGE. The samples and standards were injected hydrodynamically (50 mbar for $3 \mathrm{~s}$ ) at $25^{\circ} \mathrm{C}$ and analyzed using detection at $214 \mathrm{~nm}$. The separation voltage applied was $30 \mathrm{kV}$, with positive polarity on the injection side.

\section{Validation}

The method validation has been performed based on the parameters of linearity, selectivity, precision, accuracy, limits of detection and quantification (LOD and LOQ). Calibration curve with five levels of SA and PA in the range of $1-5 \mathrm{mg} \mathrm{L}^{-1}$ were prepared in three genuine replicates and injected in triplicate. LOD and LOQ were calculated using the equations $\mathrm{LOD}=(3.3 \times \mathrm{s}) / \mathrm{S}$ and $\mathrm{LOQ}=(10 \times \mathrm{s}) / \mathrm{S}$, where $s$ is the intercept standard deviation and $\mathrm{S}$ is the slope of the external analytical curve equation.

The precision parameter was evaluated in terms of repeatability (intra-day precision) and intermediate precision (inter-day). For intra-day, SA and PA were injected into three independent replicates and inter-day 
precision was assessed by analyzing three concentration levels of standard solutions in three independent replicates over three days. The results were expressed as the relative standard deviation (RSD), that was calculated using the equation $\mathrm{RSD}=(\mathrm{P} / \overline{\mathrm{u}}) \times 100$, where $\mathrm{P}$ is the absolute standard deviation and $\bar{u}$ is the arithmetic mean of the area ratio of the analyte to the internal standard, arithmetic mean of the migration time or corrected migration time of the analyte as a function of the internal standard migration time.

Standard addition method (SAM) was the methodology used to evaluate accuracy, where a plant extract sample was assayed, two known amount of salicylic acid was added to the samples ( 1 and $5 \mathrm{mg} \mathrm{L}^{-1}$ ) and the samples were again assayed. The difference between the results from the sample with and without the SAM was compared with the expected answer.

\section{Plant material}

Nine species of Polygala (Table 1) were collected in the south of Brazil, in the municipality of Rancho Queimado, Urubici and Florianópolis, located in the state of Santa Catarina. The collection was carried out in the morning. Part of the material was destined to the preparation of exsiccates of each species which were deposited at the Herbarium FLOR at Universidade Federal de Santa Catarina and UPCB at Universidade Federal do Paraná. The geographical coordinates, collection dates and voucher specimen are also represented in Table 1.

\section{Samples of extracts}

For the proposal of this method development, samples of extracts that were already prepared for biological activities and other tests were used. The 39 crude ethanolic extracts (CEEs) were obtained by firstly separating each species and each part of the plant, as flowers, leaves, steam and roots. Thus, they were dried, powdered and extracted using exhaustive maceration with ethanol $98 \%$, using a volume at a ratio of $1: 10(\mathrm{~m} / \mathrm{v})$, sufficient to cover the plant material at room temperature, with manual stirring every week. After one week, the CEEs were filtered on qualitative paper filter and concentrated under reduced pressure at $40{ }^{\circ} \mathrm{C}$. These steps were repeated four times in order to obtain the maximum yield of CEEs. After this process, the extracts were protected from light exposure throughout the whole process, to preserve the possibly present photosensitive secondary metabolites. After the extraction procedure, the solid mass of the extracts were weighed and stock solutions of $5000 \mathrm{mg} \mathrm{L}^{-1}$ in ethanol were prepared. The stock solutions were stored at $25^{\circ} \mathrm{C}$ until analysis. For the injection in the $\mathrm{CE}$ system, samples were diluted in water until concentration of $1000 \mathrm{mg} \mathrm{L}^{-1}$, minced, homogenized in vortex for $1 \mathrm{~min}$, ultrasonicated $(42 \mathrm{kHz})$ at $25^{\circ} \mathrm{C}$ for $1 \mathrm{~min}$ and centrifuged.

\section{Software}

The software used were Excel $^{21}$ for the statistical analyses, PeakMaster $5.4^{22,23}$ for the electrophoretic simulations and Chemstation ${ }^{20}$ for data analysis.

\section{Results and Discussion}

\section{Method development}

Capillary zone electrophoresis (CZE) is a separation methodology that attracts attention due to its great versatility and because the technique fits as a green analytical technique, allowing a reduced consumption of

Table 1. Geographical coordinates of the collection sites of the species

\begin{tabular}{|c|c|c|c|c|}
\hline \multirow{2}{*}{ Species } & \multirow{2}{*}{ Collection date } & \multicolumn{2}{|c|}{ Geographical coordinates } & \multirow{2}{*}{ Voucher specimen } \\
\hline & & Longitude & Latitude & \\
\hline Polygala pulchella & $09 / 2014$ & $27^{\circ} 40^{\prime} 21^{\prime \prime} \mathrm{S}$ & $49^{\circ} 01^{\prime} 18^{\prime \prime} \mathrm{W}$ & 28555 \\
\hline Polygala lancifolia & $08 / 2014$ & $26^{\circ} 19^{\prime} 25^{\prime \prime} \mathrm{S}$ & $49^{\circ} 18^{\prime} 26^{\prime \prime} \mathrm{W}$ & 5005 \\
\hline Polygala densiracemosa & $09 / 2014$ & $28^{\circ} 09^{\prime} 32^{\prime \prime} \mathrm{S}$ & $49^{\circ} 45^{\prime} 25^{\prime \prime} \mathrm{W}$ & 5009 \\
\hline Polygala altomontana & $10 / 2014$ & $28^{\circ} 09^{\prime} 38^{\prime \prime} \mathrm{S}$ & $49^{\circ} 37^{\prime} 10^{\prime \prime} \mathrm{W}$ & 55186 \\
\hline Polygala brasiliensis & 09/2014 & $28^{\circ} 00^{\prime} 54^{\prime \prime} \mathrm{S}$ & $49^{\circ} 35^{\prime} 30^{\prime \prime} \mathrm{W}$ & 5008 \\
\hline Polygala sabulosa & $11 / 2019$ & $27^{\circ} 40^{\prime} 58.8^{\prime \prime} \mathrm{S}$ & $49^{\circ} 08^{\prime} 54.4 " \mathrm{~W}$ & 68970 \\
\hline Polygala linoides & $11 / 2019$ & $27^{\circ} 40^{\prime} 59^{\prime \prime} \mathrm{S}$ & $49^{\circ} 08^{\prime} 54.4^{\prime \prime} \mathrm{W}$ & 68969 \\
\hline Polygala campestris & $11 / 2019$ & $27^{\circ} 40^{\prime} 58.8^{\prime \prime} \mathrm{S}$ & $49^{\circ} 08^{\prime} 54.4^{\prime \prime} \mathrm{W}$ & 68968 \\
\hline Polygala paniculata $\mathrm{D} .{ }^{\mathrm{a}}$ & $10 / 2019$ & $27^{\circ} 26^{\prime} 54.5^{\prime \prime} \mathrm{S}$ & $48^{\circ} 31^{\prime} 53.1^{\prime \prime} \mathrm{W}$ & 68967 \\
\hline Polygala paniculata $\mathrm{G}^{\mathrm{a}}$ & $03 / 2020$ & $27^{\circ} 36^{\prime} 32^{\prime \prime} \mathrm{s}$ & $48^{\circ} 26^{\prime} 17^{\prime \prime} \mathrm{W}$ & 68971 \\
\hline
\end{tabular}

${ }^{\mathrm{a}} \mathrm{D}$ was collected in Daniela Beach and G in Gravata Beach in Florianópolis. S: south; W: west. 
reagents and minimal waste generation. These methods involve the use of mobility versus $\mathrm{pH}$ curves in conjunction with simulations using software such as PeakMaster. ${ }^{22,23}$ Using this strategy, it is possible to largely eliminate the laborious task of the trial and error method or the use of factorial planning procedures in the optimization stage. Furthermore, it is also possible to use the versatility of capillary electrophoresis to increase the selectivity of the method by manipulating the analysis conditions in order to find properties that differentiate the analyte in study from other possible interfering compounds, since a plant extract is sample of high degree of complexity.

The chemical structure of SA has an aromatic ring, which allows absorption in the UV detector in CE instrument. Other important characteristic is the $\mathrm{p} K_{\mathrm{a}}$ value of 3.0 and electrophoretic mobility of $35.4 \times 10^{-5} \mathrm{~cm}^{2} \mathrm{~V}^{-1} \mathrm{~s}^{-1}$.

CZE can be used in co or counter-electroosmotic mode. In the second case, the method is commonly designed to have the velocity of the electroosmotic flow (EOF) greater than the velocity of the analyte. Another possibility would be to use a counter-electroosmotic condition in which the analyte has a velocity greater than the EOF velocity, so only analytes with a lower $\mathrm{p} K_{\mathrm{a}}$ value at low $\mathrm{pH}$ values reach the detector, thus being able to increase the selectivity. As proof of concept, all anionic analytes contained in the database of Hirokawa and $\mathrm{Kiso}^{24}$ were used. The database contains 364 anionic compounds and it is possible to divide the database into 3 large groups: $\mathrm{p} K_{\mathrm{a}}$ between -3 and 2.7 , with 88 compounds (G1), $\mathrm{p} K_{\mathrm{a}}$ 2.7 to 3.46 having 61 compounds $(\mathrm{G} 2)$ and $\mathrm{p} K_{\mathrm{a}}$ greater than 4.17 , with 215 compounds (G3). Regarding the mobilities, it is possible to divide the database into 3 groups considering absolute values $\mu_{0}>-43 \times 10^{-5} \mathrm{~cm}^{2} \mathrm{~V}^{-1} \mathrm{~s}^{-1}$ with 35 compounds $(\mathrm{G} 1 \mathrm{M}), \mu_{0}$ between -37 and $-25 \times 10^{-5} \mathrm{~cm}^{2} \mathrm{~V}^{-1} \mathrm{~s}^{-1}$ having 256 compounds (G2M) and values of $\mu_{0}<-25 \times 10^{-5} \mathrm{~cm}^{2} \mathrm{~V}^{-1} \mathrm{~s}^{-1}$ with 73 compounds (G3M). Based on this stratification of the database, it is possible to place SA in G2 and G2M groups, what made it possible to verify that, from a total of 363 possible interfering compounds (n-1), there was a large reduction in this number. So, the combination of both groups places SA in a region with a high selectivity, in which only 16 out of the 364 compounds have mobility, $\mathrm{p} K_{\mathrm{a}}$ and molar absorptivity for being possible interferences (Supplementary Information (SI), Figures S1 and S2). It is also important to note that cationic compounds migrate in the opposite direction to $\mathrm{SA}$, a selectivity that is characteristic of CZE.

In order to simulate the SA migration profile, it was necessary to know the behavior of EOF as a function of the $\mathrm{pH}$. Thus, an empirical function was adjusted to the data presented by Vitali et al., ${ }^{25}$ where the authors evaluate the behavior of the EOF in a fused silica capillary, resulting in equation 1.

$\mu_{\mathrm{osm}}=\frac{55.4}{1+\exp (7.57-1.22 \mathrm{pH})} \times 10^{-5} \mathrm{~cm}^{2} \mathrm{~V}^{-1} \mathrm{~s}^{-1}, \mathrm{R}^{2}>0.99$

where $\mu_{\text {osm }}$ is the mobility of the EOF, and $\mathrm{R}^{2}$ is the coefficient of determination.

To construct the mobility curve, equations 2 and 3 were used, where $\mu_{\mathrm{act}}$ is the mobility of the SA in the analysis condition, $\mu_{\text {eff }}$ is the effective mobility obtained using equation 3 and $\mu_{0}$ is the absolute mobility of the analyte.

$\mu_{\text {act }}=\mu_{\text {eff }}+\mu_{\text {osm }}$

$\mu_{\text {eff }}=\frac{\mu_{0}}{1+10^{\mathrm{pK}_{\mathrm{a}}-\mathrm{pH}}}$

Therefore, with the $\mathrm{p} K_{\mathrm{a}}$, ionic mobility and EOF data, it was possible to plot a curve of $\mu_{\text {act }}, \mu_{\text {osm }}$ and $\mu_{\text {eff }}$ versus $\mathrm{pH}$, presented in Figure 1, in which it can be observed that, at $\mathrm{pH}$ around 4, the SA migrates in the counter EOF mode (negative $\mu_{\text {act }}$ ) with a high $\mu_{\text {act }}$ value of approximately $-25 \times 10^{-5} \mathrm{~cm}^{2} \mathrm{~V}^{-1} \mathrm{~s}^{-1}$. Thus, under these conditions, there is an increase in selectivity as discussed above and it is possible to obtain a fast CZE method. The Figure 1 demonstrate all the mobilities behavior as the $\mathrm{pH}$ varies, showing through the result from equation $2\left(\mu_{\mathrm{act}}\right)$ that the final shape of the curve gave information for the analyte behavior in the analysis condition, which allowed to choose the $\mathrm{pH}$ around 4 for greater selectivity.

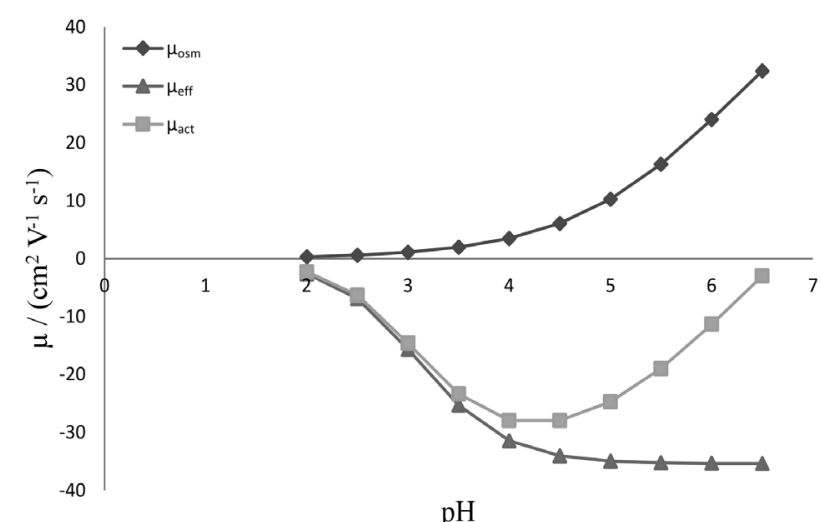

Figure 1. Mobility of $\mu_{\mathrm{acc}}, \mu_{\mathrm{osm}}$ and $\mu_{\mathrm{eff}}$ in the analysis condition versus $\mathrm{pH}$ curve.

The compounds used in the selectivity study presented before are not necessarily present in the plant matrix. Some compounds that can be present in plant extract are some phenolic acids as caffeic acid $\left(\mathrm{p} K_{\mathrm{a}} 4.62\right)$, ellagic acid 
$\left(\mathrm{p} K_{\mathrm{a}} 6.69\right)$, ferulic acid $\left(\mathrm{p} K_{\mathrm{a}} 4.68\right)$, gallic acid $\left(\mathrm{p} K_{\mathrm{a}} 4.51\right)$, 4-hydroxybenzoic acid ( $\left.\mathrm{p} K_{\mathrm{a}} 4.54\right), p$-coumaric acid $\left(\mathrm{p} K_{\mathrm{a}} 4.14\right)$, trans-cinnamic acid $\left(\mathrm{p} K_{\mathrm{a}} 4.44\right)$ and vanillic acid ( $\left.\mathrm{p} K_{\mathrm{a}} 4.16\right)$. The $\mathrm{p} K_{\mathrm{a}}$ of these compounds put them in $\mathrm{G} 3$, so that they will not be interfering with SA analysis. Other possible interfering compounds could be aliphatic acids, such as citric acid and tartaric acid, yet they do not absorb at the UV. Likewise, phenolic acids of larger chains, such as flavonoids, coumarins, xanthones, that are commonly present in plants, will also not interfere with the analysis, because in the $\mathrm{pH}$ range chosen $(\mathrm{pH}=3.9)$, these substances do not ionize. Using a procedure proposed by Spudeit et al. ${ }^{19}$ but with previous knowledge of desired $\mathrm{pH}$ (4.0), a co-ion and counter ion were chosen to increase a buffer capacity, reduced electromigration dispersion (EMD) values and an internal standard (IS). The chosen IS was phthalic acid (PA) and the BGE was composed by $15 \mathrm{mmol} \mathrm{L}^{-1}$ of Tris, $30 \mathrm{mmol} \mathrm{L}^{-1}$ of HIBA, resulting in pH 3.927, EMD -1 and -0.2 for SA and PA, respectively, with buffer capacity of $17.5 \mathrm{mmol} \mathrm{L}^{-1}$. The EOF value obtained using equation 1 at $\mathrm{pH} 3.9$ was $3.1 \mathrm{~cm}^{2} \mathrm{~V}^{-1} \mathrm{~s}^{-1}$. In order to reduce the analysis time, a capillary with the following dimensions: $\mathrm{L}_{\text {tot }}$ (total length) $32 \mathrm{~cm}$ and $\mathrm{L}_{\mathrm{det}}$ (length until detection) $8.5 \mathrm{~cm}$ (short end injection mode), was used, a voltage of $-30 \mathrm{kV}$ was applied to the $32 \mathrm{~cm}$ capillary, generating an electric field $\left(\mathrm{E}=-937.5 \mathrm{~V} \mathrm{~cm}^{-1}\right)$, so that it was possible to separate the both compounds in $0.76 \mathrm{~min}$. The optimized methodology to plant extract analysis is an extremely advantageous alternative, since the literature present methods of quality analysis of plant extracts in different applications topics, with several stages of clean-up, derivatizations, among others. This method shows how working on selectivity, studying the matrix sample can give a simple dilute-and-shoot method., ${ }^{4,6,7}$ The preparation of the samples extracts by simple dilution in water, sonication and centrifugation without the need of another treatment resulted in shorter total analysis time.

The electropherograms from the optimized method are shown in Figure 2 and Figure S2 (SI section), which displays the summarized analysis of experimental and simulated separations, demonstrating the effectiveness of PeakMaster software ${ }^{22,23}$ on the development of methods in CZE.

An oscillation in the migration time could be seen in Figure 2 when comparing the mix with the analyte and IS. These differences may be caused by many typical factors in CZE, and the fluctuation of electric field due to a sample plug composition is often the main source of this instability. The source of this fluctuation may be from the physical modification of capillary inner surface, caused most commonly by the analyte-wall interactions, formation of insoluble aggregates, and insufficient capillary rinsing. ${ }^{26}$ In order to improve reproducibility of migration time, it was used the corrected migration time, which consisted basically of using the migration time of the analyte divided by the migration time of the internal standard. The correction shows values of RSD more acceptable when comparing the RSD values for the migration time with and without the correction, around 2.0 and $6.5 \%$, respectively.

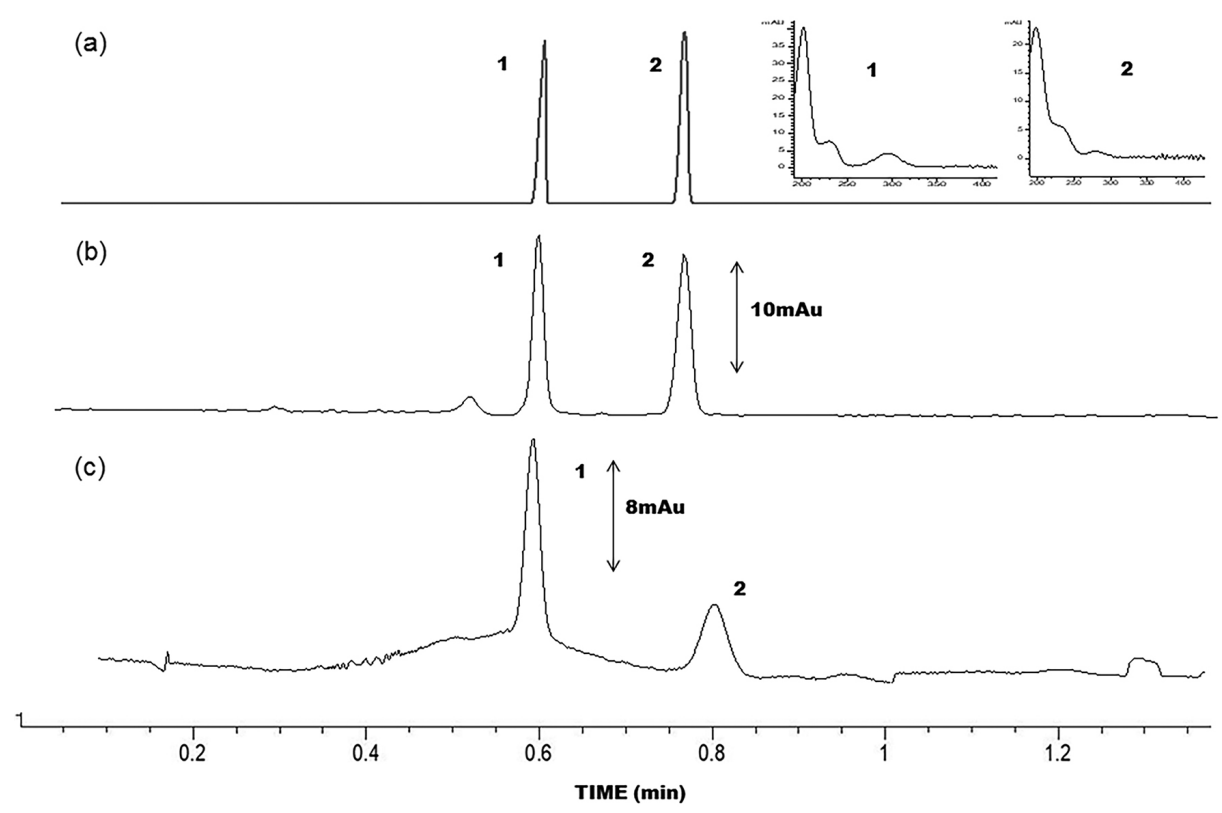

Figure 2. Electropherograms and UV spectra obtained using the optimized method by CE: (a) simulation of the analysis in PeakMaster software; (b) mix of the standard solution with $5 \mathrm{mg} \mathrm{L}^{-1}$ each; (c) sample extract of the stem of Polygala campestris. Electrolyte system composed of $15 \mathrm{mmol} \mathrm{L}^{-1}$ of Tris and $30 \mathrm{mmol} \mathrm{L}^{-1}$ of HIBA (pH 3.9), direct detection at $214 \mathrm{~nm}$. 1: salicylic acid (SA); 2: internal standard phthalic acid (PA). 
Thus, high selectivity was achieved, with the analyte of interest presenting effectively the faster mobility when compared to any other possible interfering, therefore demonstrating that the manipulation of electrophoretic conditions, taking into account the composition of the matrix, is an excellent strategy to achieve optimal selectivity. It is important to highlight that the entire strategy was elaborated in silico, with the use of few quantities of samples and reagents, which allows us to consider the method used as an eco-friendly analytical tool.

\section{Parameter of merit}

For the validation of the developed method for quantification of SA in plants, the parameters selectivity, linearity, accuracy, LOD, LOQ, precision in terms repeatability (instrumental, intra-day and inter-day precision) were verified and these results of figures of merit are shown in Table 2. The calibration curve presented a regression coefficient greater than 0.99 . The precision

Table 2. Parameters that have been analyzed for validation of CE-UV method developed to quantification of SA

\begin{tabular}{|c|c|}
\hline Parameter & SA \\
\hline Calibration curve equation ${ }^{\mathrm{a}}$ & $y=0.23 x$ \\
\hline Linearity, linear range $/\left(\mathrm{mg} \mathrm{L}^{-1}\right)$ & $1.0-5.0$ \\
\hline Linearity, slope & 0 \\
\hline Slope standard deviation & 0.23 \\
\hline Linearity, determination coefficient $\left(\mathrm{R}^{2}\right)$ & 0.99 \\
\hline $\mathrm{LOD} /\left(\mathrm{mg} \mathrm{L}^{-1}\right)$ & 0.2 \\
\hline $\mathrm{LOQ} /\left(\mathrm{mg} \mathrm{L}^{-1}\right)$ & 0.6 \\
\hline $\begin{array}{l}\text { Instrumental precision, corrected peak area } \\
(\mathrm{n}=9)(\mathrm{RSD}) / \%\end{array}$ & 4.4 \\
\hline $\begin{array}{l}\text { Instrumental precision, corrected migration time } \\
(\mathrm{n}=9)(\mathrm{RSD}) / \%\end{array}$ & 2.0 \\
\hline $\begin{array}{l}\text { Intra-day precision, corrected peak area } \\
(\mathrm{n}=9)(\mathrm{RSD}) / \%\end{array}$ & $0.7-2.9$ \\
\hline $\begin{array}{l}\text { Intra-day precision, corrected migration time } \\
(\mathrm{n}=9)(\mathrm{RSD}) / \%\end{array}$ & $2.9-2.5$ \\
\hline $\begin{array}{l}\text { Inter-day precision, corrected peak area } \\
(\mathrm{n}=27)(\mathrm{RSD}) / \%\end{array}$ & $1.0-2.7$ \\
\hline $\begin{array}{l}\text { Inter-day precision, corrected migration time } \\
(\mathrm{n}=27)(\mathrm{RSD}) / \%\end{array}$ & $0.08-0.32$ \\
\hline $\begin{array}{l}\text { Standard addition method (accuracy) - } \\
\text { Polygala pulchella roots }\end{array}$ & $108.32 \pm 19.73$ \\
\hline $\begin{array}{l}\text { Standard addition method (accuracy) - } \\
\text { Polygala linoides leaves }\end{array}$ & $115.83 \pm 7.92$ \\
\hline $\begin{array}{l}\text { Standard addition method (accuracy) - } \\
\text { Polygala linoides stems }\end{array}$ & $108.13 \pm 5.51$ \\
\hline
\end{tabular}

results for peak area were better than $2.9 \%$ (intra-day) and $2.8 \%$ (inter-day).

Standard addition method (SAM) was the methodology used to evaluate accuracy, where a plant extract sample was assayed. Two known amount of salicylic acid was added to the samples ( 1 and $\left.5 \mathrm{mg} \mathrm{L}^{-1}\right)$ and the samples were again assayed. The difference between the results from the sample with and without the SAM was compared with the expected answer, given acceptable values in 3 different samples, varying from 108 to $115 \%$ (Table 2).

\section{Sample analysis}

The optimized method was applied to quantify SA in the sample extracts previously prepared, whose quantitation results are presented in Table 3.

Contents of SA in the species of Polygala demonstrate higher accumulation of SA in the species of Polygala campestris, Polygala sabulosa and Polygala paniculata. A common feature found in the quantification is that the SA content in the stem parts of all plant species presents higher concentrations in general, none below the LOQ. This characteristic possibly refers to a defense mechanism of these species, in response or repellency to herbivore attacks, since these species have long stems and are small shrubs.,

SA can be synthesized by hydroxylation of the phenylpropanoid pathway and is metabolized to methyl$\mathrm{SA}$, a volatile resistance inducer that characterizes the plants of the genus Polygala. ${ }^{3}$ The high contents of SA in a plant species leave some assumptions, since the literature ${ }^{27}$ brought that SA influences the accumulation of some special metabolites as terpenes in different plants species already studied. One of those examples found in literature ${ }^{1}$ is the Centella asiatica specie, which enhanced the total triterpenoid contents mediated via the overexpression of key genes in biosynthesis pathway, when treated with exogenous SA. Elevated triterpenoid contents enhanced its anti-inflammatory activity and certainly other biological properties are also improved. ${ }^{1}$

\section{Comparison with reported methods}

A brief comparison among the methods allowed us to conclude that only this proposed method determines the SA in plant matrices using CZE with the shortest separation time. In addition, it is important to mention that the values of LOD, LOQ and precision were at equivalent levels to the mentioned methods, being considered adequate for the proposed application. The comparative analysis of the mentioned methods shows that CZE has many advantages 
Table 3. Quantitation results for SA for the plant extracts samples

\begin{tabular}{|c|c|c|}
\hline Specie and part of the plant & $\begin{array}{c}\text { Mass / } \\
\left(\mathrm{mg} \mathrm{kg}^{-1}\right)\end{array}$ & $\begin{array}{c}\text { Standard } \\
\text { deviation (SD) }\end{array}$ \\
\hline Polygala pulchella leaves & 94.814 & 27.027 \\
\hline Polygala pulchella stems & 375.105 & 157.654 \\
\hline Polygala pulchella flowers & $<$ LOD & - \\
\hline Polygala pulchella roots & 87.438 & 4.003 \\
\hline Polygala linoides leaves & $<$ LOD & - \\
\hline Polygala linoides stems & 247.606 & 27.178 \\
\hline Polygala linoides flowers & 352.792 & 45.819 \\
\hline Polygala linoides roots & $<$ LOD & - \\
\hline Polygala campestris leaves & 167.080 & 61.325 \\
\hline Polygala campestris stems & 1353.304 & 62.683 \\
\hline Polygala campestris flowers & 93.652 & 26.040 \\
\hline Polygala campestris roots & 64.328 & 11.328 \\
\hline Polygala brasiliensis leaves & $<$ LOD & - \\
\hline Polygala brasiliensis stems & 142.245 & 23.632 \\
\hline Polygala brasiliensis flowers & $<\mathrm{LOD}$ & - \\
\hline Polygala brasiliensis roots & $<$ LOD & - \\
\hline Polygala sabulosa leaves & 344.993 & 384.899 \\
\hline Polygala sabulosa stems & 479.358 & 103.687 \\
\hline Polygala sabulosa flowers & 310.823 & 42.851 \\
\hline Polygala sabulosa roots & 308.980 & 6.624 \\
\hline Polygala paniculata D. $^{\mathrm{a}}$ leaves & 113.437 & 36.670 \\
\hline Polygala paniculata D. ${ }^{\mathrm{a}}$ stems & 113.684 & 9.096 \\
\hline Polygala paniculata D. ${ }^{\mathrm{a}}$ flowers & 505.948 & 3.845 \\
\hline Polygala paniculata D. ${ }^{\mathrm{a}}$ roots & 993.906 & 64.858 \\
\hline Polygala paniculata $\mathrm{G}^{\text {a }}$ leaves & 164.424 & 101.013 \\
\hline Polygala paniculata G. $^{\mathrm{a}}$ stems & 299.350 & 17.299 \\
\hline Polygala paniculata G. ${ }^{a}$ flowers & 125.678 & 4.004 \\
\hline Polygala paniculata $\mathrm{G} .{ }^{\mathrm{a}}$ roots & 148.607 & 29.264 \\
\hline Polygala lancifolia leaves & 159.384 & 53.655 \\
\hline Polygala lancifolia stems & 169.377 & 24.159 \\
\hline Polygala lancifolia flowers & 107.615 & 52.645 \\
\hline Polygala densiracemosa leaves & 158.376 & 9.245 \\
\hline Polygala densiracemosa stems & 120.008 & 17.564 \\
\hline Polygala densiracemosa flowers & $<$ LOD & - \\
\hline Polygala densiracemosa roots & 98.722 & 46.482 \\
\hline Polygala altomontana leaves & 116.930 & 1.715 \\
\hline Polygala altomontana stems & 119.428 & 38.679 \\
\hline Polygala altomontana flowers & 115.196 & 57.645 \\
\hline Polygala altomontana roots & 95.305 & 13.469 \\
\hline
\end{tabular}

a D was collected in Daniela Beach and G in Gravata Beach in Florianópolis. LOD: limit of detection.

in relation to other techniques, besides the method developed does not request the need for derivatization or other critical laborious steps.

\section{Conclusions}

The new rapid method developed for the quantification of SA, an elicitor of secondary metabolites in plant matrices, through capillary electrophoresis with UV detection, allowed us to assume relevant information about these species with important medicinal characteristics in the Southern region of Brazil. The development of a subminute method that allowed the quantification of an elicitor such as SA, in plants, with low limits of detection and quantification, high selectivity, low consumption of organic solvents and short time for sample preparation, collaborated significantly in the screening of bioactive compounds in Polygala species. It was possible to identify and highlight the high concentration of SA in the extracts from the stems of all species, and specifically higher values for Polygala campestris and roots of Polygala paniculata. Such quantification allowed an evaluation of the phytochemical and phytopharmaceutical potential of these plants.

\section{Supplementary Information}

Supplementary data are available free of charge at http://jbcs.sbq.org.br as PDF file.

\section{Acknowledgments}

The authors are grateful to INCT-Catálise (Instituto Nacional de Ciência e Tecnologia) for financial support, FAPESC (Fundação de Amparo à Pesquisa e Inovação do Estado de Santa Catarina, No. 2019TR0847), as well as CAPES (Coordenação de Aperfeiçoamento de Pessoal de Nível Superior) for the K. H. S. L. scholarship.

\section{References}

1. Ali, B.; Biocatal. Agric. Biotechnol. 2020, 101884.

2. Lefevere, H.; Bauters, L.; Gheysen, G.; Front. Plant Sci. 2020, 11,338 .

3. Murphy, A. M.; Zhou, T.; Carr, J. P.; Curr. Opin. Virol. 2020, 42,8 .

4. Bensemmane, N.; Bouzidi, N.; Daghbouche, Y.; Garrigues, S.; de la Guardia, M.; El Hattab, M.; Phytochem. Anal. 2021, 32, 206.

5. Ding, P.; Ding, Y.; Trends Plant Sci. 2020, 25, 549.

6. Sharma, A.; Kumar, I.; Rana, K.; Int. J. Pharm. Pharm. Sci. 2020, 41.

7. El-Yazbi, A. F.; Aboukhalil, F. M.; Khamis, E. F.; Youssef, R. M.; El-Sayed, M. A.; Microchem. J. 2021, 163, 105900.

8. Liu, J.; Liu, A.; Mao, F.; Zhao, Y.; Cao, Z.; Cen, N.; Li, S.; Ind. Crops Prod. 2019, 134, 113. 
9. Zhao, Z.; Bai, Y.; Xie, J.; Chen, X.; He, X.; Sun, Y.; Bai, Y.; Zhang, Y.; Wu, S.; Zheng, X.; Bioorg. Chem. 2019, 88, 102832.

10. Wang, L.; Jin, G.; Yu, H.; Li, Q.; Yang, H.; Neurosci. Lett. 2019, 705, 195.

11. Tizziani, T.; Pereira, M.; Venzke, D.; Missau, F. C.; Ruani, A. P.; Montagner, D. F.; Pizzolatti, M. G.; Micke, G. A.; Brighente, I. M. C.; Biochem. Syst. Ecol. 2018, 78, 46.

12. Shi, T.; Jiang, Y.; J. Chin. Pharm. Sci. 2013, 22, DOI: 10.5246/ jcps.2013.01.004.

13. Lacaille-Dubois, M. A.; Delaude, C.; Mitaine-Offer, A. C.; Triterpenoid Saponins: A Focus on Polygalaceae; Ramawat, K.; Mérillon, J. M., eds.; Natural Products Springer: Berlin, Germany, 2013, p. 3205.

14. Lacaille-Dubois, M. A.; Delaude, C.; Mitaine-Offer, A. C.; J. Ethnopharmacol. 2020, 249, 112417.

15. Borges, F. R. M.; Silva, M. D.; Córdova, M. M.; Schambach, T. R.; Pizzolatti, M. G.; Santos, A. R. S.; J. Ethnopharmacol. 2014, 151, 144.

16. Arruda-Silva, F.; Nascimento, M. V. P. S.; Luz, A. B. G.; Venzke, D.; Queiroz, G. S.; Fröde, T. S.; Pizzolatti, M. G.; Dalmarco, E. M.; Int. Immunopharmacol. 2014, 19, 334.

17. Xin, T.; Zhang, F.; Jiang, Q.; Chen, C.; Huang, D.; Lv, Y.; Shen, W.; Jin, Y.; Carbohydr. Polym. 2012, 90, 1671.

18. Lapa, F. R.; Gadotti, V. M.; Missau, F. C.; Pizzolatti, M. G.; Marques, M. C. A.; Dafré, A. L.; Farina, M.; Rodrigues, A. L. S.; Santos, A. R. S.; Basic Clin. Pharmacol. Toxicol. 2009, 104, 306.
19. Spudeit, D. A.; Gonçalves, S.; Bretanha, L. C.; Claumann, C. A.; Machado, R. A. F.; Micke, G. A.; J. Braz. Chem. Soc. 2016, 27, 1974.

20. 3D-CE ChemStation; Agilent Technologies, Santa Clara, CA, United States, 2001-2010.

21. Microsoft Excel; Microsoft Corporation, USA, 2010.

22. Gas, B.; Jaroš, M.; Hruška, V.; Zuskova, I.; Štědrý, M.; LC.GC Eur. 2005, 18, 282.

23. Jaros, M.; Stedry, M.; Hruska, V.; Zuskova, I.; Gas, B.; PeakMaster, 5.4; Charles University, Prague-Czech Republic, 2011.

24. Hirokawa, T.; Kiso, Y.; J. Chromatogr. 1982, 252, 33.

25. Vitali, L.; Della Betta, F.; Costa, A. C. O.; Vaz, F. A. S.; Oliveira, M. A. L.; Vistuba, J. P.; Fávere, V. T.; Micke, G. A.; Talanta 2014, 123, 45.

26. Nowak, P. M.; Woźniakiewicz, M.; Gładysz, M.; Janus, M.; Kościelniak, P.; Anal. Bioanal. Chem. 2017, 409, 4383.

27. Gacnik, S.; Veberic, R.; Marinovic, S.; Halbwirth, H.; MikulicPetkovsek, M.; Sci. Hortic. 2021, 277, 109794.

Submitted: July 22, 2021

Published online: September 28, 2021 